\title{
Timing in the Absence of Supraspinal Input II: Regularly Spaced Stimulation Induces a Lasting Alteration in Spinal Function That Depends on the NMDA Receptor, BDNF Release, and Protein Synthesis
}

\author{
Kyle M. Baumbauer, John R. Huie, Abbey J. Hughes, and James W. Grau \\ Department of Psychology, Texas A\&M University, College Station, Texas 77843-4325
}

The detection of temporal regularity allows organisms to predict the occurrence of future events. When events occur in an irregular manner, uncertainty is increased, and negative outcomes can ensue (e.g., stress). The present study shows that spinal neurons can discriminate between variable- and fixed-spaced stimulation and that the detection of regularity requires training and engages a form of NMDA receptor-mediated plasticity. The impact of stimulus exposure was assessed using a spinally mediated instrumental response, wherein spinally transected rats are given legshock whenever one hindlimb is extended. Over time, they learn to maintain the leg in a flexed position that minimizes net shock exposure. Prior exposure to 180-900 tailshocks given in a variable (unpredictable) manner inhibited this learning. A learning deficit was not observed when 900 tailshocks were applied using a fixed (predictable) spacing. Fixed-spaced stimulation did not have a divergent effect when fewer (180) shocks were presented, implying that the abstraction of temporal regularity required repeated exposure (training). Moreover, fixed-spaced stimulation both prevented and reversed the learning deficit. The protective effect of fixed-spaced shock lasted $48 \mathrm{~h}$, and was prevented by pretreatment with the NMDA receptor antagonist MK-801. Administration of the protein synthesis inhibitor cycloheximide after training blocked the long-term effect. Inhibiting BDNF function, using TrkB-IgG, also eliminated the beneficial effect of fixed-spaced stimulation. The results suggest that spinal systems can detect regularity and that this type of stimulation promotes adaptive plasticity, which may foster recovery after spinal injury.

\section{Introduction}

Organisms can gain an adaptive advantage by detecting regularity across time and space, allowing for the prediction of future events on the basis of past experience. For some closely spaced stimuli (e.g., sound waves between 20 and 20,000 Hz), predesigned neural systems may automatically detect regularity, providing the neural cues that underlie our ability to perceive pitch and texture (Griffiths et al., 1998; Hall et al., 2005; Yau et al., 2009). As the gap between events is increased, detecting regularity becomes more difficult and may require a form of learning (temporal conditioning) to encode that the interval between events reliably predicts the occurrence of the next event. In the absence of this learning, and other predictive (Pavlovian) cues, there is a high level of temporal uncertainty. For biologically significant events, temporal uncertainty introduces a form of chaos that can enhance stress and undermine function (Overmier and Seligman, 1967; Seligman and Maier, 1967; Shors et al., 1990), thereby favoring the evolution of neural mechanisms that can detect regularity.

\footnotetext{
Received July 23, 2009; revised Sept. 2, 2009; accepted Sept. 21, 2009.

The present work was supported by National Institute of Neurological Disorders and Stroke Grants NS51443 and NS041548, and National Institute of Child Health and Human Development Grant HD058412. We thank Dr. Michelle Hook, Denise Puga, Kevin Hoy, and Georgina Moreno for their helpful comments.

Correspondence should be addressed to Kyle M. Baumbauer at the above address. E-mail: baumbauer@ tamu.edu.

D01:10.1523/JNEUROSCI.3583-09.2009

Copyright $\odot 2009$ Society for Neuroscience $\quad$ 0270-6474/09/2914383-11\$15.00/0
}

Researchers have often attributed the abstraction of temporal relations to neural systems within the brain (Ivry and Spencer, 2004; Mauk and Buonomano, 2004; Karmarkar and Buonomano, 2007). However, recent research suggests that even simple systems have some capacity to abstract temporal relations. For example, in a brain slice preparation, an extended series (900) of low-frequency $(1 \mathrm{~Hz})$ pulses generally yields long-term depression (LTD) when the stimuli are presented in a regular manner (Dudek and Bear, 1992; Mulkey and Malenka, 1992). Presenting the same number of stimuli in a variable manner undermines the development of LTD and enhances signs of long-term potentiation (Perrett et al., 2001). Likewise, in the isolated spinal cord, repeated stimulation of the sciatic nerve has divergent effects on plastic function depending upon whether the stimuli occur in a fixed or variable manner; 900 shock pulses given in a variable manner disrupts subsequent learning whereas the same number of shocks given in a regular manner do not (Baumbauer et al., 2008). Interestingly, variable- and fixed-spaced shock both induce a learning deficit when fewer (180) shocks are given. Only after extended training (720 additional shocks) does fixed-spaced stimulation produce a divergent effect, an outcome that suggests that the underlying process may involve a form of learning.

Using a spinal preparation, we now show that an extended exposure to fixed-spaced stimulation not only reverses the learning deficit, it evokes a lasting protective effect that blocks the adverse consequences of variable stimulation. The protective ef- 
fect evoked by fixed-spaced stimulation depends on a form of NMDA receptor (NMDAR)-mediated plasticity, protein synthesis, and the neurotrophin BDNF. The results demonstrate that the isolated spinal cord can discriminate variable- and fixedspaced stimulation, that these two forms of stimulation have divergent functional consequences, and that the abstraction of regularity depends on neurochemical systems implicated in learning and memory.

\section{Materials and Methods}

Subjects. Male Sprague Dawley rats obtained from Harlan were used as subjects. Rats were 70-90 d old and weighed 350-400 g at the time of spinal cord transection. They were housed in pairs with ad libitum access to food and water, and were maintained on a $14-10 \mathrm{~h}$ light-dark cycle. All experiments were performed in accordance with National Institutes of Health (NIH) standards for the care and use of laboratory animals (NIH publication No. 80-23), and were approved by the University Laboratory Animal Care Committee at Texas A\&M University. Every effort was made to minimize suffering and limit the number of animals used.

Spinalization surgery. Before surgery, the fur over the thoracic portion of the vertebral column was shaved and disinfected with betadine solution (H-E-B). Rats were anesthetized with isoflurane gas. The rat's head was rendered immobile in a stereotaxic apparatus with a small $(5 \times 4 \times$ $2.5 \mathrm{~cm}$ ) gauze pillow under the subject's chest. An anterior-to-posterior incision was made over the second thoracic vertebrae (T2), the tissue immediately rostral to $\mathrm{T} 2$ was cleared using rongeurs, and the cord was exposed and cauterized. The remaining gap in the cord was filled with Gelfoam (Pharmacia), and the wound was closed with Michel clips (Fisher Scientific). Following closure of the wound, the surface of each leg was shaved for electrode placement. Intraperitoneal injections $(3 \mathrm{ml})$ of $0.9 \%$ saline solution were administered postoperatively to prevent dehydration. Following surgery, rats were placed in a temperature-controlled environment $\left(25.5^{\circ} \mathrm{C}\right)$ and monitored until awake. All rats were checked every six to $8 \mathrm{~h}$ during the $18-24 \mathrm{~h}$ postsurgical period. During this time, hydration was maintained with supplemental injections of saline, and the rats' bladders and colons were expressed as necessary.

Spinal transections were confirmed by inspecting the cord under a $10 \times$ dissection scope, and observing the behavior of the subjects after they recovered to ensure that they exhibited paralysis below the level of the forepaws and did not exhibit any supraspinally mediated pain responses to legshock.

Tailshock. Tailshock was applied using a shock electrode constructed from a modified fuse clip. The electrode was coated with electrode paste and attached to the tail with Orthaletic tape. Leads from the fuse clip were attached to a BRS/LVE shock generator (Model SG-903). To induce a learning deficit, 6 min of tailshock ( $1.5 \mathrm{~mA} \mathrm{AC})$ was administered on a variable interstimulus interval (ISI; range $=0.2-3.8 \mathrm{~s}$, mean ISI of $2 \mathrm{~s}, 80$ $\mathrm{ms}$ duration). This shock procedure has been found to generate a reliable deficit in spinal learning that lasts for at least $48 \mathrm{~h}$ (Crown et al., 2002). To examine how fixed ISI stimulation affected performance, tailshock was administered on a $2 \mathrm{~s}$ ISI ( $1.5 \mathrm{~mA}$ AC $80 \mathrm{~ms}$ duration). A $2 \mathrm{~s}$ ISI was used to match the mean interval in the variable condition, allowing us to equate other factors (e.g., duration of restraint) across conditions. Further, prior work indicated that variable- and fixed-spaced stimulation had divergent effects at this ISI (Baumbauer et al., 2008).

Learning procedures. The apparatus used was similar to that described by Grau et al. (1998). Briefly, during instrumental testing all subjects were loosely restrained in Plexiglas tubes, with their hindlimbs suspended above a rectangular plastic dish $(11.5 \mathrm{~cm}$ [width $(\mathrm{w})] \times 19 \mathrm{~cm}$ [length (l)] $\times 5 \mathrm{~cm}$ [depth (d)]) containing a saline solution positioned $7.5 \mathrm{~cm}$ below the restraining tube. Holes were drilled into the anterior portion of the tubes to allow for ventilation. Two slots were cut $4 \mathrm{~cm}$ apart and $1.5 \mathrm{~cm}$ from the posterior end of the tube to allow both hind legs to hang freely. To monitor leg position, a stainless-steel rod [ $7 \mathrm{~cm}(\mathrm{l})$, $0.46 \mathrm{~mm}(\mathrm{w})]$ was attached to the pad of one foot (contact electrode) extending past the toes. The contact electrode was taped to the plantar surface of the rat's foot [Orthaletic, $1.3 \mathrm{~cm}$ (width); Johnson and John- son] with the end positioned directly in front of the plantar protuberance. Heat-shrink tubing electrically insulated the rod from the paw. A fine wire $\left(0.01 \mathrm{~mm}^{2}\right.$ [36 American wire gauge (AWG)], magnet wire single beldsol) was attached to the end of the rod at a point under the insulation. This wire extended from the rear of the foot and was connected to a digital input board that was monitored by a Macintosh G4 computer. To minimize lateral leg movements, a piece of porous tape [Orthaletic, $1.3 \mathrm{~cm}$ (width)] was wrapped around the leg above the tarsus and attached under the front panel of the restraining tube.

Two electrodes were then inserted into one hindleg. The first electrode was constructed of stainless-steel wire $\left[0.05 \mathrm{~mm}^{2}\right.$ (30 AWG) $]$ and was inserted through the skin over the tibia, $1.5 \mathrm{~cm}$ from the tarsus. The second was made of fine wire $\left[0.01 \mathrm{~mm}^{2}\right.$ (36 AWG), magnet wire single beldsol] and was inserted perpendicular to the leg, through the body of the tibialis anterior muscle, $1.7 \mathrm{~cm}$ above the first electrode. Legshock was applied by attaching one lead from a constant current AC shock generator (Model SG-903; BRS/LVE) to the electrode inserted into the tibialis anterior muscle. The second lead was attached to the wire implanted in the skin over the tibia. Shock $(60 \mathrm{~Hz}, \mathrm{AC})$ intensity was adjusted for each subject to a level that produced a $0.4 \mathrm{~N}$ flexion response. This value was determined before instrumental training by looping a monofilament plastic line ("6lb." test strength; DuPont) around the rat's ankle. The end of the line was attached to a strain gauge (Fort-1000; World Precision Instruments) fastened to a ring stand. The strain gauge output was fed through a calibrated multimeter that allowed for a conversion from voltage to force in newtons. To determine the necessary flexion force, a single $300 \mathrm{~ms}$ shock was applied to the leg and the shock intensity was adjusted so that all subjects displayed a $0.4 \mathrm{~N}$ flexion response. After flexion force was set, the monofilament line was removed from the rat's paw and the saline solution was adjusted so that the contact electrode sat $4 \mathrm{~mm}$ beneath the surface of the salt solution. Once the animals were prepared, the 30 min instrumental testing session began. Whenever the subjects' legs were extended, the end of the rod contacted the saline solution and completed an electrical circuit. When the circuit was closed, shock was delivered to the tibialis anterior muscle, which elicited a flexion response. The flexion response broke the circuit and terminated the shock.

Drug administration. Drugs were administered intrathecally using a 10 $\mu \mathrm{l}$ Hamilton syringe attached to the exposed end of each subject's intrathecal cannula. MK-801 and cycloheximide (Sigma-Aldrich) were each dissolved into $10 \mu \mathrm{l}$ of $0.9 \%$ saline, and TrkB-IgG (R\&D Research) was dissolved into $1 \mu \mathrm{l}$ of $0.9 \%$ saline. Each compound was administered at a constant rate over a period of several minutes. Following each injection cannulae were flushed with $20 \mu \mathrm{l}$ of $0.9 \%$ saline.

Behavioral measures of learning. Training and testing sessions were divided into thirty $1 \mathrm{~min}$ bins to examine learning across trials. Response number and response duration were collected by the computer during these sessions, and were separately averaged across each $1 \mathrm{~min}$ bin. Every time the contact electrode left the solution, the number of responses was increased by one. The computer also recorded the amount of time the electrode remained out of the solution. Response duration served as the primary measure of learning and was calculated for each $1 \mathrm{~min}$ bin using the following equation: response duration $=($ time out of solution $) \div$ (response number +1 ).

Statistics. Baseline shock threshold intensities, initial response durations, and response duration over time were analyzed using a mixeddesign ANOVA, analysis of covariance (ANCOVA), or trend analyses. Where appropriate, Tukey's honestly significant difference (HSD) was used to conduct post hoc analyses. Significant group differences are indicated in the figures with an "*." In all cases, $p<0.05$ was used to determine statistical significance.

Measures of baseline behavioral reactivity. To verify that our experimental manipulations did not impair the subject's capacity to exhibit a flexion response, we assessed both the shock intensity needed to elicit a $0.4 \mathrm{~N}$ flexion force and the duration of the first flexion response at the start of testing. The average shock intensity needed to elicit a $0.4 \mathrm{~N}$ flexion force was $0.56 \pm 0.02 \mathrm{~mA}$ (mean $\pm \mathrm{SE}$ ) and the mean duration of the first response was $0.15 \pm 0.01 \mathrm{~s}$. As observed in past studies, few differences in baseline reactivity were observed across experiments and emerged with a frequency that seemed ascribable to chance, with one significant group 
difference observed in shock intensity and another in initial flexion duration (both $F$ values $>3.60, p<0.05$ ). To assure that these baseline differences did not contribute to our test results, we analyzed the data from these experiments using an analysis of covariance (ANCOVA), treating the baseline score that yielded a significant difference as a covariate.

Response number. Elsewhere, we have shown that treatments that disrupt learning (as indexed by a decrease in response duration) do not undermine the subjects' capacity to perform the target response. Indeed, subjects that fail to learn typically exhibit the highest rates of responding (Grau et al., 1998). A similar pattern was observed in the present experiments. For example, in the first six experiments reported below, subjects that had previously received variable shock exhibited little change in response duration over the $30 \mathrm{~min}$ of testing, but maintained a high level of responding [146.24 \pm 37.86 (mean $\pm \mathrm{SE}$ )]. As a result, these subjects repeatedly experienced the response-outcome relation, but did not exhibit an increase in response duration (our index of instrumental learning). In contrast, subjects that had received no treatment (unshocked controls), or 24-30 min of fixed-spaced shock, before testing exhibited a progressive increase in response duration and a concomitant decrease in response number $(21.84 \pm 15.53)$ (all $F$ values $>1.88, p<0.01$ ). Because (1) our measure of learning (response duration) and response number covaried (in an inverse manner) across experiments, (2) the former avoids some interpretative problems (see Grau et al., 1998), and (3) our analyses of response number yielded no surprising results, we focus our subsequent analyses on response duration.

\section{Results}

Our initial evidence that spinal neurons can learn about temporal spacing came from a series of experiments examining how stimulation of the sciatic nerve impacts a simple form of instrumental conditioning, wherein optimal performance depends upon learning about a response-outcome relationship. In a prototypical study, one group (master) of spinally transected (spinalized) rats is given shock to one hindlimb whenever that leg is extended (Grau et al., 2006). These subjects exhibit a progressive increase in flexion duration that reduces net shock exposure. Subjects in a second group are experimentally coupled (yoked) to the master rats and receive shock at the same time, and for the same duration, but independent of leg position. These subjects do not exhibit an increase in flexion duration. Further, exposure to uncontrollable stimulation undermines subsequent instrumental learning, a learning deficit reminiscent of the behavioral phenomenon of learned helplessness (Overmier and Seligman, 1967; Seligman and Maier, 1967).

To further analyze the mechanisms that underlie the learning deficit, we developed a computer program that emulated the distribution of shocks produced by a typical master subject during the first 5-10 min of training (Crown et al., 2002). During this period, master rats typically received approximately thirty $80 \mathrm{~ms}$ shocks per minute, yielding a mean ISI of $2 \mathrm{~s}$. Because master subjects exhibit some variability in the duration of each flexion response, the interval between shocks varied. We emulated this property by varying the ISI between 0.2 and $3.8 \mathrm{~s}$ (rectangular distribution). Using these parameters, we showed that just 6 min of shock (180 pulses) to the leg or tail disrupted spinal learning for 24-48 h. Further work has shown that the induction of the learning effect depends on protein synthesis, the mGlu, GABA, and NMDA receptors, protein kinase $\mathrm{C}$, and a ligand (presumably, substance $\mathrm{P}$ ) that acts on the neurokinin receptor (Ferguson et al., 2003, 2006, 2008; Patton et al., 2004; Baumbauer et al., 2007).

To further explore the neural mechanisms that underlie the induction of the learning deficit, we evaluated the consequences of electrophysiological stimulation applied to the sciatic nerve
(Baumbauer et al., 2008). Assuming that spinal mechanisms cannot discriminate variable- and fixed-spaced stimulation, we presented stimuli in a regular manner, a step we thought would simplify the derivation of the effective frequency range. As a safeguard, we verified that 180 shocks applied to the sciatic nerve induced a learning deficit regardless of whether the stimuli occurred in a fixed or variable manner. However, when the duration of training was increased fivefold (to 900 shocks), a surprising outcome emerged. As in past studies (Crown et al., 2002; Ferguson et al., 2006; Baumbauer et al., 2008), variable stimulation produced a learning deficit, but fixed-spaced shock had no adverse effect.

The present experiments demonstrate that fixed-spaced stimulation does much more than reverse the learning deficit-it induces a lasting protective effect that blocks the induction of the learning deficit through a process that depends on the NMDAR, protein synthesis, and the neurotrophin BDNF.

\section{Training with extended variable-, but not fixed-, spaced stimulation undermines learning}

Our claim that fixed and variable stimulation have distinct effects on spinal cord function, and that the consequences of fixed-spaced stimulation depend on training, rests on single experiment using an invasive shock procedure. Here we sought evidence that a similar pattern of results could be obtained using the noninvasive shock procedures used in prior studies. The experiment also seeks to extend the generality of the phenomenon by demonstrating that fixed-spaced shock applied to a remote location (the tail) can impact learning when subjects are tested with legshock. Spinalized rats were given 0,6 , or $30 \mathrm{~min}$ of variable (ISI = $0.2-3.8 \mathrm{~s}$, mean $=2 \mathrm{~s}$ ) or fixed ISI (2s) stimulation through cutaneous tail electrodes ( $n=6$ subjects/condition). We then tested subjects under common conditions in our instrumental learning paradigm.

When tested with response-contingent legshock, previously unshocked rats exhibited a progressive increase in response duration, while subjects given 6 min of variable- or fixed-spaced shock (180 shocks) failed to learn (Fig. 1A). When shock exposure was increased fivefold (900 shocks), only variable shock produced a learning deficit (Fig. $1 B$ ). An ANOVA revealed significant main effects of shock treatment (unshocked, fixed, or variable), duration of exposure (6 vs $30 \mathrm{~min}$ ), and time bin (all $F$ values $\geq 8.10, p<0.001$ ). Most importantly, the impact of shock treatment depended upon both duration of exposure $\left(F_{(2,30)}=\right.$ $4.35, p<0.05)$ and time $\left(F_{(58,870)}=2.78, p<0.001\right)$. There was also a three-way interaction between shock treatment, duration, and time $\left(F_{(58,870)}=2.01, p<0.001\right)$. No other differences approached statistical significance $\left(F_{(29,870)}<1.0, p>0.05\right)$. Post hoc comparisons of the group means demonstrated that both unshocked groups and subjects that received fixed-spaced shock for $30 \mathrm{~min}$ had significantly longer response durations than subjects in all other conditions $(p<0.05)$.

\section{Fixed-spaced stimulation reverses the learning deficit}

Six minutes (180 shocks) of intermittent shock produced a learning deficit, independent of whether the interval between shocks was variable or fixed. However, when the duration of stimulation was increased to $30 \mathrm{~min}$ (900 shocks), only variable-spaced shock impaired subsequent learning. Because 6 min of fixed stimulation yielded a learning deficit, it appears that continued exposure to fixed-spaced shock can reverse the deficit. If this is true, then exposure to 24 min (720 shocks) of fixed-spaced shock may reverse the adverse effect of 180 shocks given in a variable manner. To examine whether fixed-spaced stimulation can have such a 
therapeutic effect, subjects received 0 or 6 min of variable-spaced tailshock followed by 0 or $24 \mathrm{~min}$ of fixed-spaced tailshock (Fig. 2). Subjects were then tested for 30 min in our instrumental learning para$\operatorname{digm}(n=8$ subjects/condition).

Unshocked rats, and those that received fixed-spaced shock alone, exhibited an increase in flexion duration over the 30 min test period (Fig. $2 \mathrm{~A}$ ). Rats that received variable-spaced stimulation alone exhibited a learning deficit, while those that received fixed-spaced shock after variable stimulation learned at test. An ANOVA revealed significant main effects of variable- and fixed-spaced shock treatment (both $F$ values $>6.85, p<0.05$ ). Most importantly, the interaction term showed that the impact of variable shock treatment depended upon whether subjects subsequently received fixed-spaced $\operatorname{shock}\left(F_{(1,28)}=6.68, p<0.05\right)$. The main effect of time and the time by variable shock interaction were also significant (both $F$ values $>2.11, p<0.01$ ). No other differences approached statistical significance (all $F$ values $<1.05, p>0.05$ ). Post hoc comparison of group means confirmed that subjects given variable-spaced shock alone had significantly shorter response durations than subjects in all other conditions $(p<0.05)$.

Fixed-spaced stimulation reverses the learning deficit observed $24 \mathrm{~h}$ after variable shock

In our first two experiments, subjects were tested immediately after shock treatment. Elsewhere, we have shown that the learning deficit observed after variable shock lasts at least $24 \mathrm{~h}$ (Crown et al., 2002). Instituting a regular relation could induce a shortterm effect that temporarily blocks the expression of the deficit. If this is true, the deficit may reemerge if testing is delayed. To address this possibility we repeated the previous experiment but tested subjects 24 h later ( $n=6$ subjects/condition).

As before, unshocked subjects, as well as subjects that only received fixed-spaced shock, were capable of acquiring and maintaining a prolonged flexion response (Fig. $2 \mathrm{~B}$ ). Subjects that received variable shock alone $24 \mathrm{~h}$ earlier failed to learn. Subjects that were given fixed-spaced shock immediately after variable stimulation were able to learn when tested $24 \mathrm{~h}$ later. Because there was a slight, but statistically significant, difference in the shock intensity required to elicit a $0.4 \mathrm{~N}$ flexion at the start of testing, an ANCOVA was used to analyze the test results (with the baseline shock intensity entered as the covariate). This analysis confirmed that the impact of variable shock treatment depended upon whether subjects later received fixed-spaced shock, yielding a significant three-way interaction with time $\left(F_{(29,551)}=2.14, p<\right.$ 0.01 ). No other effects approached statistical significance (all $F$ values $<1.20, p>0.05$ ). Post hoc comparisons of the group means confirmed that subjects treated with variable stimulation alone had shorter response durations than subjects in all other conditions $(p<0.05)$.

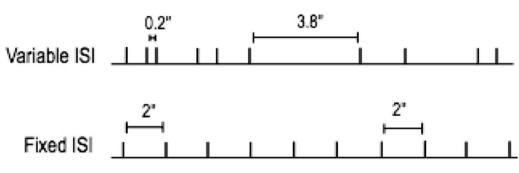

$6 \min$

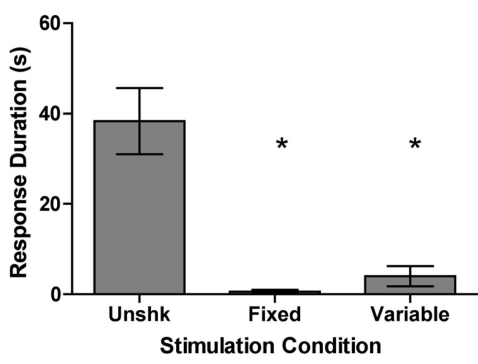

$30 \min$

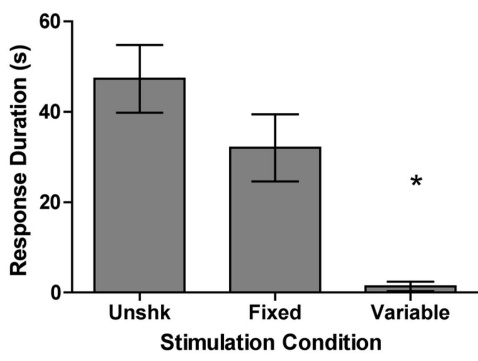

Figure 1. The effect of training with 6 or $30 \mathrm{~min}$ of fixed or variable-spaced stimulation on performance. Subjects received 6 or 30 min of tailshock on a variable or fixed spacing before testing. The upper panels $(\boldsymbol{A})$ represent data from subjects that received 6 列 indicate groups that were significantly different from the unshocked controls $(p<0.05)$, and error bars indicate \pm SE. The inset illustrates variable (range $=0.2-3.8 \mathrm{~s}$, mean $=2 \mathrm{~s}$ ) versus fixed-spaced $(2 \mathrm{~s})$ stimulation.

\section{Fixed-spaced stimulation reverses the learning deficit when administered $24 \mathrm{~h}$ after deficit induction}

Prior work has shown that disrupting de novo protein synthesis soon after shock treatment eliminates the learning deficit (Patton et al., 2004; Baumbauer et al., 2006). If drug administration is delayed by $6 \mathrm{~h}$, it has no effect, implying that the long-term effect of VT stimulation depends on active cellular processes that continue for a few hours after shock treatment (Baumbauer et al., 2006). In the previous two experiments, fixed-spaced stimulation had a therapeutic effect when given immediately after variable shock. Here too, delayed treatment may have less of an effect. To examine this possibility, subjects ( $n=6$ subjects/condition) received 0 or 6 min of variable-spaced shock. The next day, they were given 0 or 24 min of fixed-spaced tailshock and were then tested for $30 \mathrm{~min}$ with response-contingent legshock (Fig. 3).

Unshocked subjects, as well as subjects that received fixedspaced shock alone, were capable of learning at test (Fig. 3). Subjects administered variable stimulation alone exhibited a learning deficit. Exposure to fixed-spaced shock $24 \mathrm{~h}$ after variable stimulation eliminated the learning deficit. An ANOVA confirmed that the impact of variable shock treatment depended upon whether subjects later received fixed-spaced shock, yielding both a significant two-way interaction between variable- and fixedspaced shock treatments $\left(F_{(1,20)}=19.75, p<0.001\right)$ and a threeway interaction with time $\left(F_{(29,580)}=1.72, p<0.05\right)$. The main effects of variable-spaced shock, fixed-spaced shock, and time were also significant (all $F$ values $>12.63, p<0.001$ ), as were the remaining interaction terms (both $F$ values $>1.98, p<0.01$ ). 


\begin{tabular}{|c|c|c|c|}
\hline 1 & II & \multirow{4}{*}{$\begin{array}{c}0 \text { or } \\
24 \mathrm{hr}\end{array}$} & III \\
\hline Unshocked & Unshocked & & \\
\hline 6'Variable & Unshocked & & Test \\
\hline Unshocked & $24^{\prime}$ Fixed & & \\
\hline 6'Variable & 24' Fixed & & \\
\hline
\end{tabular}

A Immediate Test
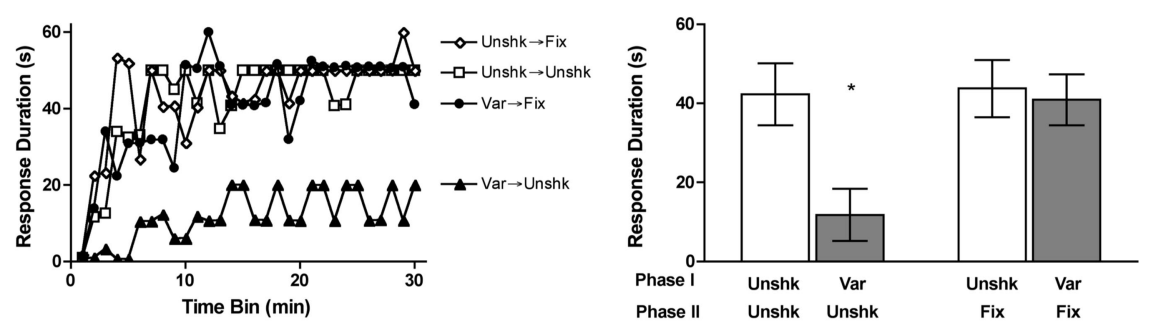

$B$

Delayed Test
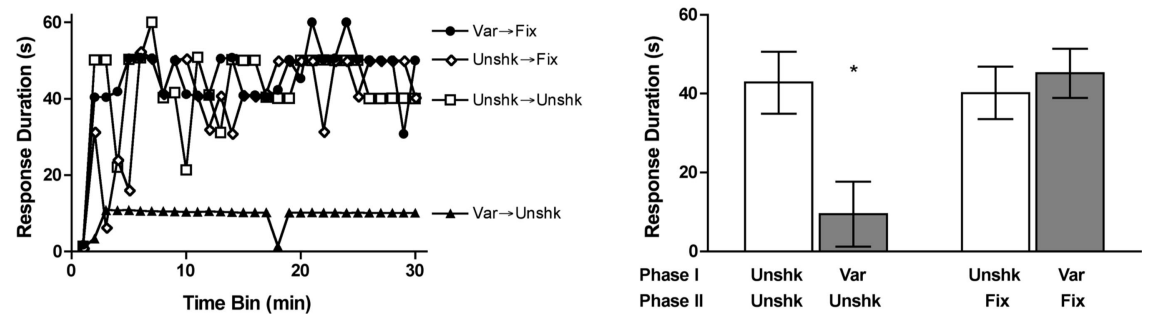

Figure 2. Fixed-spaced stimulation reverses the learning deficit produced by variable shock. Subjects received 0 or 6 min of variable-spaced tailshock followed by 0 or 24 min of fixed-spaced shock (see inset). Testing occurred 0 (top panels; $A$ ) or $24 \mathrm{~h}$ (lower panels; $\boldsymbol{B}$ ) after tailshock. The panels on the left depict response durations across time for subjects that received no shock (open squares; Unshk $\rightarrow$ Unshk), 6 min of variable stimulation followed by no shock (closed triangles; $\mathrm{Var} \rightarrow$ Unshk), no shock followed by 24 min of fixed stimulation (open diamonds; Unshk $\rightarrow$ Fix), or 6 min of variable shock followed by 24 min of fixed shock (closed circles; $\mathrm{Var} \rightarrow \mathrm{Fix}$ ). The panels on the right show subjects' average response durations collapsed across time. Asterisks indicate groups that were significantly different from subjects that received no shock $(p<0.05)$, and error bars represent \pm SE.
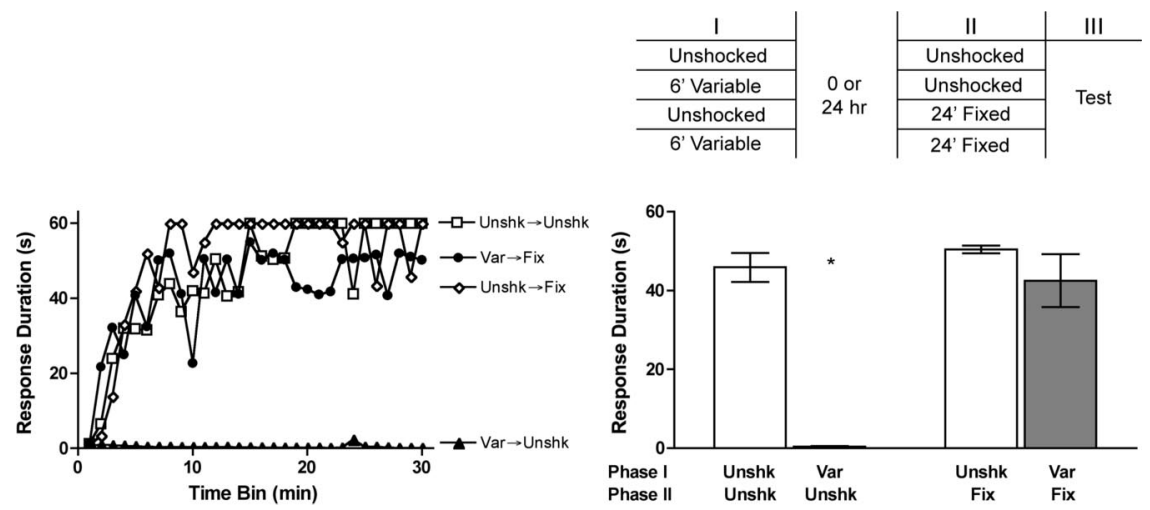

Figure 3. Fixed-spaced stimulation reverses the learning deficit when administered $24 \mathrm{~h}$ following variable shock. Subjects received 0 or $6 \mathrm{~min}$ of variable-spaced tailshock $24 \mathrm{~h}$ before treatment with 0 or $24 \mathrm{~min}$ of fixed stimulation (see inset). Testing occurred immediately following fixed-spaced shock. The left panel shows response durations over time for subjects that received no shock (open squares; Unshk $\rightarrow$ Unshk), 6 min of variable stimulation followed by no shock (closed triangles; $V a r \rightarrow$ Unshk), no shock followed by 24 min of fixed stimulation (open diamonds; Unshk $\rightarrow$ Fix), or 6 min of variable shock followed by 24 min of fixed shock (closed circles; $\mathrm{Var} \rightarrow \mathrm{Fix}$ ). The panel on the right shows subjects' average response durations collapsed across time. Asterisks indicate groups that were significantly different from subjects that received no shock $(p<0.05)$, and error bars represent \pm SE.

\section{Fixed-spaced stimulation blocks the induction of the learning deficit}

Fixed-spaced stimulation has a therapeutic capacity that can reverse the antagonistic effect of variable shock on learning. We next examined whether prior treatment with fixed-spaced stimulation has a protective effect that can prevent deficit induction. Subjects were given 0 or 24 min of fixed-spaced tailshock followed by 0 or 6 min of variable-spaced tailshock. Once treatment with tailshock was completed, instrumental learning was assessed immediately ( $n=6$ subjects/condition) or $24 \mathrm{~h}$ ( $n=6$ subjects/condition) later.

When tested immediately after treatment (Fig. 4A), we found that both unshocked controls and subjects given fixed-spaced shock alone exhibited an increase in flexion duration over time. Subjects given variable shock alone failed to learn, and this learning deficit was eliminated by prior exposure to fixed-spaced shock. An ANOVA revealed significant main effects of fixed stimulation, variable stimulation, and time (all $F$ values $>4.82$, $p<0.05)$. The interactions between variable stimulation and time $\left(F_{(29,580)}=\right.$ 2.23, $p<0.001)$ and between fixed stimulation and variable stimulation $\left(F_{(1,20)}=\right.$ 5.34, $p<0.05)$ were also significant. The latter effect emerged because subjects treated with variable stimulation alone had significantly shorter response durations than subjects in the other conditions. No other effects approached significance (all $F$ values $<1.40, p>0.05$ ).

The same pattern of results was obtained when testing was delayed for $24 \mathrm{~h}$ (Fig. 4B). Again, both unshocked controls and those given fixed-spaced shock alone learned. Rats that had previously received variable shock alone failed to learn and this learning deficit was eliminated by prior exposure to fixed-spaced shock. An ANOVA revealed significant main effects of fixed stimulation, variable stimulation, and trials (all $F$ values $>5.38$, $p<0.001)$. Importantly, there was also a significant fixed stimulation by variable stimulation interaction $\left(F_{(1,20)}=9.42\right.$, $p<0.01)$. This significant interaction emerged because subjects that received variable shock alone had shorter response durations than subjects in all other conditions. No other statistical effects approached significance (all $F$ values $<1.30$, $p>0.05$ ).

\section{The protective effect of fixed-spaced stimulation lasts $24-48 \mathrm{~h}$}

The previous experiment showed that exposure to fixed-spaced shock immediately before variable stimulation blocked the induction of the learning deficit. The current experiment examined whether exposure to fixed-spaced shock would inhibit the induction of the learning deficit when exposure to variable stimulation was delayed by $24-48 \mathrm{~h}$. Subjects received 0 or 24 min of fixed-spaced tailshock followed by 0 or $6 \mathrm{~min}$ of variablespaced tailshock 24 ( $n=6$ subjects/condition) or $48 \mathrm{~h}(n=8$ subjects/condition) later. Immediately after the second stimulation period, subjects were tested for instrumental learning.

When a $24 \mathrm{~h}$ gap separated fixed and variable shock exposure (Fig. 5A), we found that rats given fixed-spaced shock alone, or that remained unshocked, exhibited an increase in response du- 
ration over the course of testing. Rats that received variable shock alone failed to learn and this learning deficit was blocked by pretreatment with fixed-spaced shock given $24 \mathrm{~h}$ earlier. An ANOVA revealed significant main effects of fixed stimulation, variable stimulation, and time (all $F$ values $>7.70$, $p<0.001$ ), as well as a significant fixed stimulation by variable stimulation interaction $\left(F_{(1,28)}=5.52, p<0.05\right)$. This significant interaction emerged because subjects treated with variable shock alone had shorter response durations than subjects in all other conditions. No other effects approached statistical significance (all $F$ values $<1.30, p>0.05$ ).

The same pattern of results was obtained when $48 \mathrm{~h}$ intervened between fixed and variable shock treatment (Fig. $5 B)$. Again, subjects in the unshocked and fixed stimulation alone conditions were capable of learning, while subjects that received variable stimulation alone were not. Rats that received fixed stimulation $48 \mathrm{~h}$ before variable stimulation learned at test. An ANOVA revealed significant main effects of fixed stimulation, variable stimulation, and time (all $F$ values $>5.95$, $p<0.05)$. No other effects approached significance (all $F$ values $<3.30, p>0.05$ ). Although the overall three-way interaction between stimulation conditions and trials was not statistically significant $\left(F_{(29,812)}<1.0, p>0.05\right)$, trend analyses revealed significant quadratic $\left(F_{(1,812)}=4.94, p<0.05\right)$ and cubic $\left(F_{(1,812)}=6.95, p<0.01\right)$ components that accounted for $24.45 \%$ and $34.41 \%$ of the variance, respectively. These trends emerged because subjects that received variable stimulation alone had shorter response durations than subjects in all other conditions.

\section{Pretreatment with a NMDA antagonist blocks the acquisition of the fixed-spaced effect}

NMDAR activation is critical for initiating the neuronal modifications that accompany many forms of learning (Morris et al., 1986; Rodrigues et al., 2004). If the effects of fixed-spaced stimulation reflect a form of learning, the long-term consequence of fixed stimulation may likewise depend on NMDAR function. To examine the role of the NMDAR, subjects ( $n=6$ subjects/condition) were administered $10 \mathrm{nmol}(1 \mu \mathrm{l} \mathrm{vol})$ of the NMDAR antagonist MK-801 or saline (i.t.) followed by a $20 \mu \mathrm{l}$ saline flush. This dose of MK-801 was used because it has been shown to block spinally mediated instrumental learning and its pharmacological action wanes within $24 \mathrm{~h}$ (Ferguson et al., 2006). To verify that administration of MK-801 had no long-term effects on behavior, animals were given an injection of MK-801 or saline (i.t.) before $24 \mathrm{~min}$ of restraint on day 1 and were tested $24 \mathrm{~h}$ later. The average response duration for subjects administered saline was $27.11 \pm 8.25 \mathrm{~s}$, while the mean response duration for subjects given MK-801 was $35.66 \pm 8.17$ s. Our analysis confirmed that prior drug treatment had no impact on instrumental learning. An ANOVA yielded a significant main effect of time bin $\left(F_{(29,290)}=\right.$ $3.06, p<0.001)$, indicating that subjects exhibited a progressive increase in response duration during testing. No other statistical effects approached significance (all $F$ values $<1.00, p>0.05$ ).

\begin{tabular}{|c|c|c|c|}
\hline I & II & \multirow{5}{*}{$\begin{array}{c}0 \mathrm{hr} \\
\text { or } \\
24 \mathrm{hr}\end{array}$} & III \\
\hline Unshocked & Unshocked & & \multirow{4}{*}{ Test } \\
\hline Unshocked & 6'Variable & & \\
\hline 24' Fixed & Unshocked & & \\
\hline 24' Fixed & 6' Variable & & \\
\hline
\end{tabular}

Immediate Test
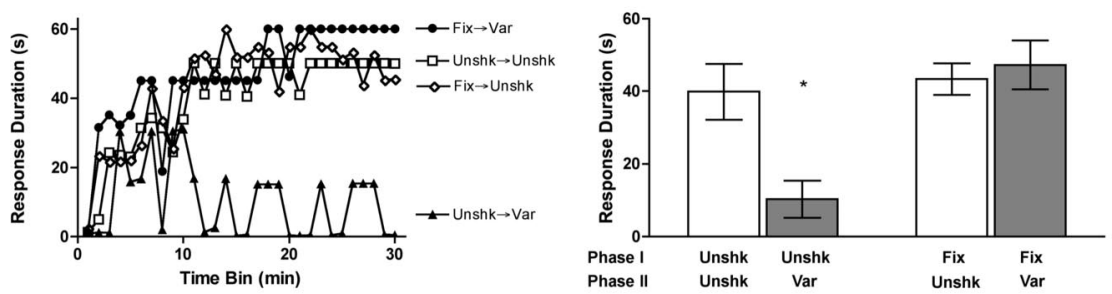

Delayed Test

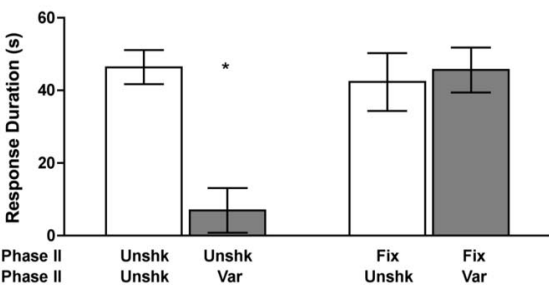

Figure 4. Fixed-spaced stimulation protects against deficit induction. Subjects received 0 or $24 \mathrm{~min}$ of fixed-spaced tailshock (top panels; $\boldsymbol{A}$ ) or $24 \mathrm{~h}$ (lower panels; $\boldsymbol{B}$ ) following were significantly different from subjects that received no shock $(p<0.05)$, and error bars represent \pm SE.

Having established that drug treatment per se has no longterm effect, we tested whether pretreatment with MK-801 blocks the long-term protective effect of fixed-spaced stimulation. Subjects ( $n=6$ subjects/condition) received saline or MK-801 15 min before 0 or 24 min of fixed-spaced tailshock. Twenty-four hours later, subjects were administered 6 min of variable-spaced shock and were tested in the instrumental learning paradigm.

As expected, subjects that received variable-spaced stimulation alone (regardless of drug treatment) exhibited a learning deficit at test (Fig. 6). Fixed-spaced stimulation in the absence of MK-801 had a protective effect that blocked the induction of the learning deficit. This protective effect was blocked by pretreatment with MK-801. An ANOVA revealed a main effect of fixed stimulation $\left(F_{(1,20)}=6.14, p<0.05\right)$ and a significant drug condition by fixed stimulation interaction $\left(F_{(1,20)}=5.11\right.$, $p<0.05)$. This interaction emerged because only saline-treated subjects that had received fixed-spaced stimulation acquired the instrumental response during testing. No other statistical effects approached significance (all $F$ values $<2.10, p>0.05$ ).

\section{The long-term effect of fixed-spaced stimulation depends on de novo protein synthesis}

In many learning paradigms, long-term modifications (memory) depend on protein synthesis (Flexner et al., 1965; Davis and Squire, 1984; Nader et al., 2000; Schafe and LeDoux, 2000). Here we examined whether the long-term effect of fixed-spaced shock also requires de novo protein synthesis. To address this question, subjects received $36 \mathrm{nmol}(10 \mu \mathrm{l} \mathrm{vol})$ of cycloheximide or saline (i.t.) and a $20 \mu \mathrm{l}$ saline flush. This dose was chosen because it blocks the consolidation of the learning deficit and because its pharmacological action wanes within 24 h (Patton et al., 2004). 
A
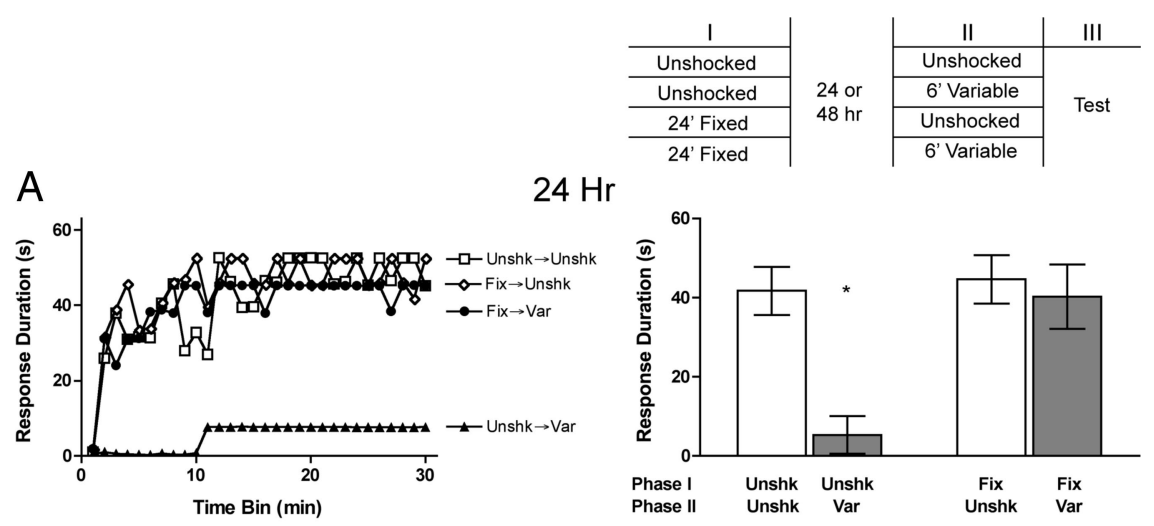

B

$48 \mathrm{Hr}$
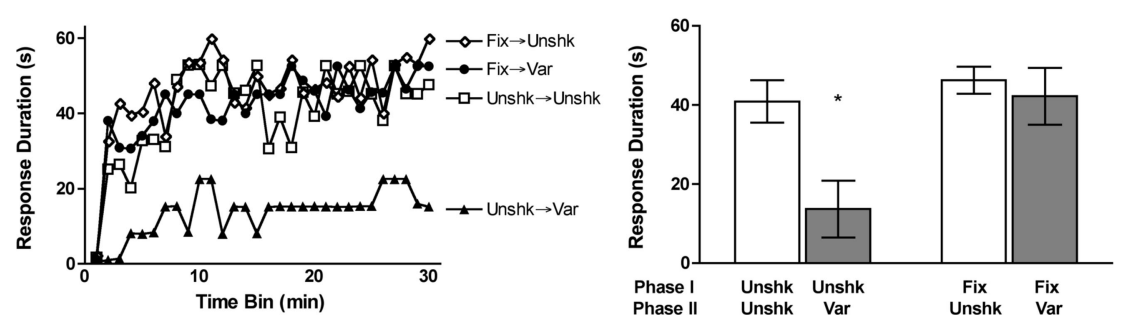

Figure 5. The protective effect of fixed-spaced stimulation persists for $24-48 \mathrm{~h}$. Subjects received 0 or 24 min of fixed-spaced tailshock followed 24 (top panels; $\boldsymbol{A}$ ) or $48 \mathrm{~h}$ (bottom panels; $\boldsymbol{B}$ ) later by 0 or $6 \mathrm{~min}$ of variable-spaced shock (see inset). Testing occurred immediately following variable stimulation. The panels on the left depict response durations across time for subjects that received no shock (open squares; Unshk $\rightarrow$ Unshk), no shock followed by 6 min of fixed stimulation (closed triangles; Unshk $\rightarrow$ Var), 24 min of fixed stimulation followed by no shock (open diamonds; Fix $\rightarrow$ Unshk), or 24 min of fixed shock followed by 6 min of variable shock (closed circles; Fix $\rightarrow$ Var). The panels on the right show subjects' average response durations collapsed across time. Asterisks indicate groups that were significantly different from subjects that received no shock ( $p<0.05)$, and error bars represent $\pm S E$.

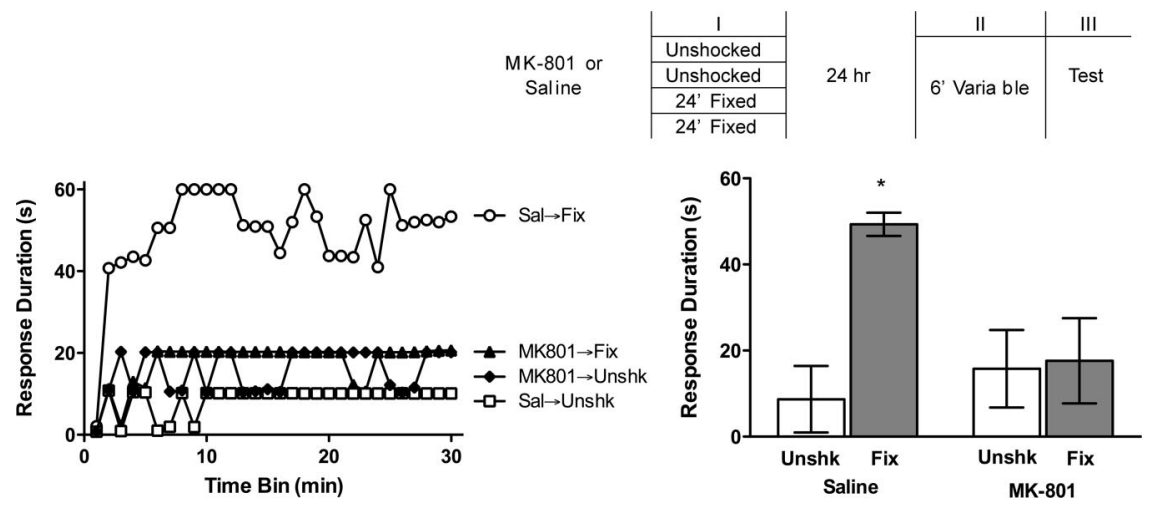

Figure 6. The protective effect of fixed-spaced stimulation is NMDAR dependent. Subjects received $10 \mathrm{nmol}$ of MK- 801 or saline before application of 0 or 24 min of fixed-spaced tailshock (see inset). Twenty-four hours later, subjects were given 6 min of variable-spaced shock immediately followed by instrumental test. Data are depicted for subjects that received saline before $0 \mathrm{~min}$ of fixed stimulation (open squares; Sal $\rightarrow$ Unshk), saline before 24 min of fixed stimulation (open circles; Sal $\rightarrow$ Fix), MK-801 before 0 min of fixed stimulation (closed diamonds; MK801 $\rightarrow$ Unshk), or MK-801 before 24 min of fixed stimulation (closed triangles; MK801 $\rightarrow$ Fix). The panel on the left depicts response durations across time, while the panel on the right shows subjects' average response durations collapsed across trials. Asterisks indicate groups that were significantly different from subjects that received saline and 0 min of fixed stimulation ( $p<0.05)$, and error bars represent $\pm S E$.

To verify that drug treatment has no long-term effect, we administered cycloheximide or saline and tested subjects $24 \mathrm{~h}$ later. The mean response duration for subjects given saline was $39.16 \pm$ $7.41 \mathrm{~s}$ and the average response duration for rats given cycloheximide was $44.42 \pm 7.81 \mathrm{~s}$. An ANOVA confirmed that subjects exhibited an increase in response duration over time $\left(F_{(29,290)}=\right.$ 6.23, $p<0.001)$ and that there was no residual effect of drug treatment (all $F$ values $<1.30, p>0.05$ ).
We then examined whether administration of cycloheximide immediately after exposure to fixed-spaced shock blocks its long-term protective effect. Subjects ( $n=6 /$ condition) received 0 or $24 \mathrm{~min}$ of fixed-spaced tailshock, immediately followed by $36 \mathrm{nmol}$ of cycloheximide or saline (i.t.) Twenty-four hours following stimulation, subjects received $6 \mathrm{~min}$ of variable-spaced tailshock, immediately followed by instrumental testing.

As expected, subjects that received variable stimulation alone, regardless of drug treatment, failed at test (Fig. 7). Fixed-spaced shock had a protective effect in the vehicle controls, and administration of cycloheximide eliminated this protective effect. An ANOVA yielded significant main effects of fixed stimulation $\left(F_{(1,19)}=21.50, p<0.001\right)$, drug treatment $\left(F_{(1,19)}=15.77, p<0.01\right)$, and time $\left(F_{(29,551)}=2.47, p<0.001\right)$, as well as a significant interaction between fixed stimulation and drug treatment $\left(F_{(1,19)}=\right.$ 16.39, $p<0.001$ ). In addition, all of the two-way and three-way interactions with time were significant (all $F$ values $>1.65, p<0.05)$. Post hoc comparisons confirmed that rats treated with saline following fixed-spaced stimulation maintained significantly longer response durations than subjects in the other conditions $(p>0.05)$.

\section{The protective effect of fixed stimulation requires $\mathrm{BDNF}$ release} We have shown that controllable stimulation produces an upregulation in BDNF mRNA levels (Gómez-Pinilla et al., 2007), and that blocking BDNF undermines the beneficial effects of controllable shock (Huie et al., 2006). To examine whether this neurotrophin mediates the protective effect of fixed-spaced stimulation, subjects ( $n=8$ subjects/condition) were administered 4.5 or $9.0 \mathrm{pmol}(10 \mu \mathrm{l} \mathrm{vol})$ of the BDNF sequestering molecule TrkBIgG or saline followed by a $20 \mu \mathrm{l}$ saline flush. These doses are within the range known to impact the beneficial effect of instrumental learning (Gómez-Pinilla et al., 2007). To verify that drug treatment per se had no long-term effect on instrumental performance, subjects were given 4.5 or 9.0 pmol of TrkB-IgG or saline (i.t.) before $30 \mathrm{~min}$ of restraint and were tested $24 \mathrm{~h}$ later (Fig. $8 \mathrm{~A}$ ). As usual, subjects exhibited a progressive increase in response duration over time $\left(F_{(29,609)}=9.93, p<0.05\right)$. More importantly, there was no indication that prior drug treatment affected test performance (all $F$ values $<1.0, p>0.05$ ).

We then examined whether pretreatment with TrkB-IgG would block the protective effect of fixed-spaced shock. Subjects received 0.0 ( $n=12$ subjects/condition), 4.5 ( $n=12$ subjects/ 
condition), or $9.0 \mathrm{pmol}$ ( $n=8$ subjects/ condition) $30 \mathrm{~min}$ before treatment with 0 or 24 min of fixed-spaced shock. Immediately following fixed stimulation subjects receive 0 or $6 \mathrm{~min}$ of variable-spaced shock. Instrumental learning was assessed $24 \mathrm{~h}$ later.

Regardless of drug treatment, subjects given variable stimulation alone exhibited a learning deficit (Fig. 8B). Fixed stimulation produced a protective effect in subjects that received saline, and this protective effect was blocked by TrkB-IgG treatment. An ANCOVA (which controlled for variation in baseline performance) revealed a significant main effect of time $\left(F_{(29,986)}=\right.$ $1.58, p<0.05)$, and significant drug by shock condition $\left(F_{(1,34)}=7.26, p<0.05\right)$ and drug by shock by time $\left(F_{(29,986)}=\right.$ 2.16, $p<0.001$ ) interactions. Subsequent analyses revealed that rats treated with saline before fixed-spaced stimulation maintained significantly longer flexion durations than all other subjects $(p<$ $0.05)$. No other statistical effects approached significance (all $F$ values $<1.00$, $p>0.05)$.

An extended exposure to regularly spaced shock evokes an NMDAR-dependent process that alters the long-term consequences of stimulation. Engaging this process appears to have two consequences. First, it eliminates the deficit that normally accrues early in training. Second, it engages a protective effect that inhibits the subsequent induction of the learning deficit. The above results suggest that this protective effect depends on the release of BDNF. What is not clear is whether BDNF also plays a role in the biological process that underlies the abstraction of regularity across time and the elimination of any degradative effect due to shock exposure per se. If BDNF is involved in either of these processes, pretreatment with TrkB-IgG should cause fixed-spaced shock to have a variable shock like effect and induce a learning deficit. To explore this possibility, subjects ( $n=8$ subjects/condition) were administered 4.5 or 9.0 pmol of TrkB-IgG or saline i.t. followed by a $20 \mu \mathrm{l}$ saline flush. Thirty minutes following drug administration, subjects received $24 \mathrm{~min}$ of fixed-spaced tailshock. The capacity for instrumental learning was assessed $24 \mathrm{~h}$ later. The average response duration for subjects administered saline was $35.49 \pm$ $8.06 \mathrm{~s}$, while the mean response durations for subjects given 4.5 and 9.0 pmol of TrkB-IgG were $35.38 \pm 7.22 \mathrm{~s}$ and $23.06 \pm 7.76 \mathrm{~s}$, respectively. Our analysis demonstrated that all subjects were capa-
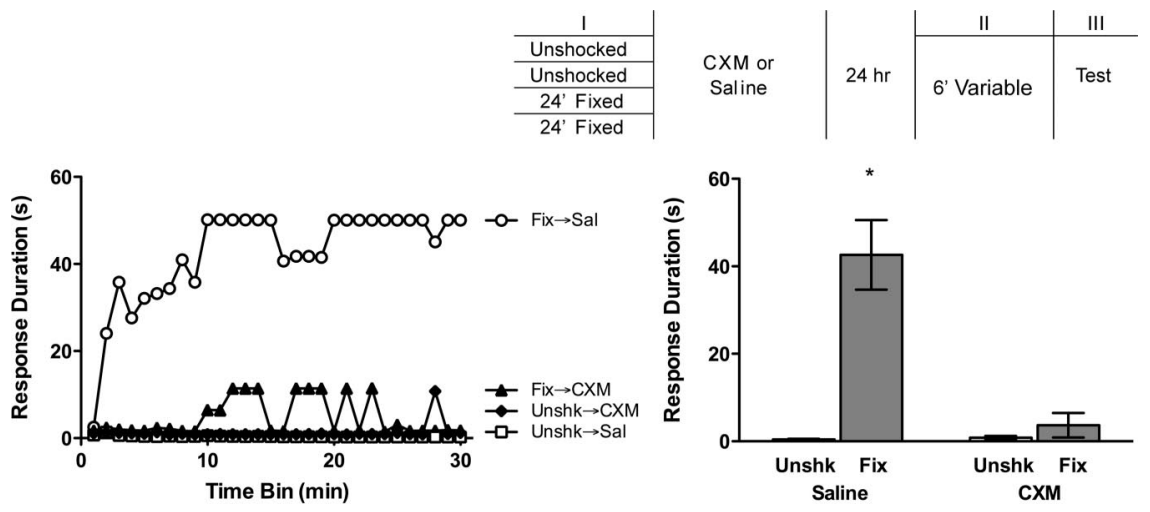

Figure 7. The protective effect of fixed-spaced stimulation requires protein synthesis. Subjects received 0 or 24 min of fixedspaced tailshock followed by intrathecal administration of cycloheximide (10 nmol) or saline (see inset). Twenty-four hours later, subjects were given 6 min of variable-spaced shock immediately followed by instrumental test. Data are shown for subjects that received 0 min of fixed stimulation before saline (open squares; Unshk $\rightarrow$ Sal), 24 min of fixed stimulation before saline (open circles; Fix $\rightarrow$ Sal), 0 min of fixed stimulation before cycloheximide (closed diamonds; Unshk $\rightarrow$ (XM), or 24 min of fixed stimulation before cycloheximide (closed triangles; Fix $\rightarrow(X M)$. The panel on the left depicts response durations across time, while the panel on the right shows subjects' average response durations collapsed across trials. Asterisks indicate groups that were significantly different from subjects that received 0 min of fixed stimulation and saline $(p<0.05)$, and error bars represent \pm SE.

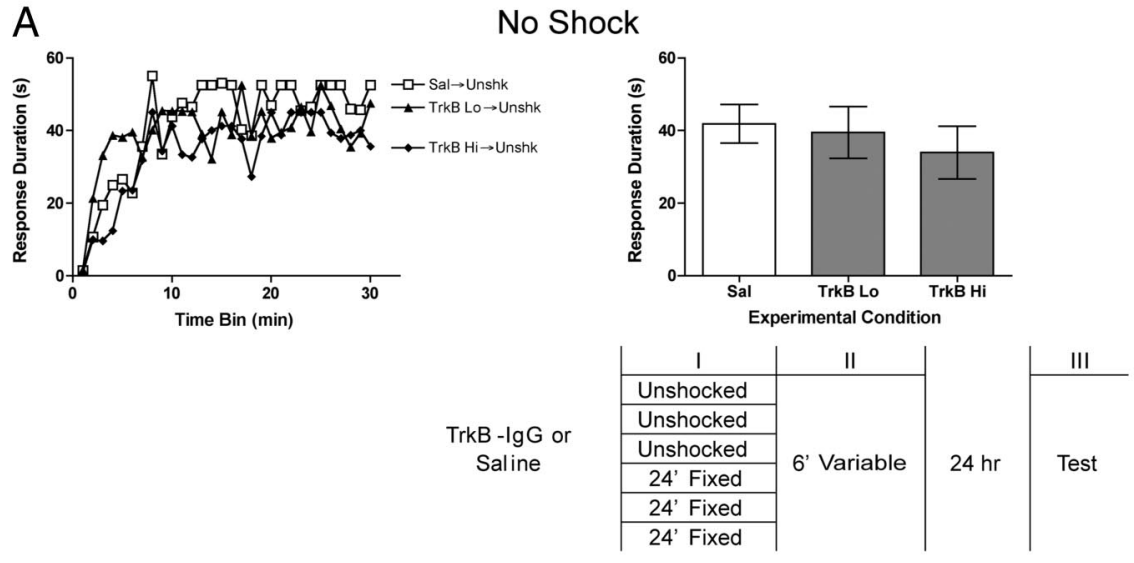

B Tailshock
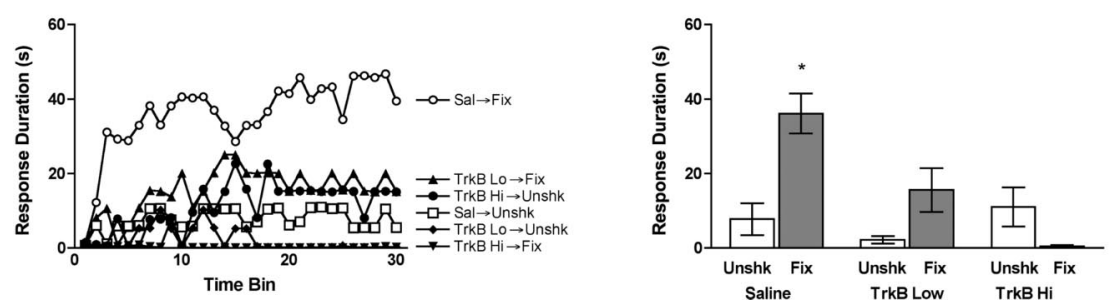

Figure 8. Sequestering BDNF eliminates the protective effect of fixed stimulation. Subjects received 0, 4.5, or $9.0 \mathrm{pmol}$ of TrkB-IgG before application of 0 or 24 min of fixed-spaced tailshock (see inset). Immediately following fixed stimulation rats were administered 6 min of variable-spaced shock. Testing occurred $24 \mathrm{~h}$ later. The upper panels $(\boldsymbol{A})$ depict data for unshocked controls that received saline (open squares; Sal $\rightarrow$ Unshk), $4.5 \mathrm{pmol}$ of TrkB-lgG (closed triangles; TrkB Lo $\rightarrow$ Unshk), or $9.0 \mathrm{pmol}$ of TrkB-IgG (closed diamonds; TrkB Hi $\rightarrow$ Unshk). The lower panels $(\boldsymbol{B})$ show data for subjects that received saline before 0 min of fixed stimulation (open squares; Sal $\rightarrow$ Unshk), saline before 24 min of fixed stimulation (open circles; Sal $\rightarrow$ Fix), 4.5 pmol of TrkB-lgG before 0 min of fixed stimulation (closed diamonds; TrkB Lo $\rightarrow$ Unshk), 9.0 pmol of TrkB-lgG before 0 min of fixed stimulation (closed circles; TrkB Hi $\rightarrow$ Unshk), $4.5 \mathrm{pmol}$ of TrkB-lgG before $24 \mathrm{~min}$ of fixed stimulation (closed upward triangles; TrkB L0 $\rightarrow$ Fix), or 9.0 pmol of TrkB-lgG before 24 min of fixed stimulation (closed downward triangles; TrkB Hi $\rightarrow$ Unshk). The panels on the left depict response durations across time, while the panels on the right show subjects' average response durations collapsed across trials. Asterisks indicate groups that were significantly different from subjects that received saline and 0 min of fixed stimulation ( $p<0.05)$, and error bars represent \pm SE. 
ble of maintaining a prolonged flexion response over time $\left(F_{(1,21)}=10.89, p<0.01\right)$, and that there was no evidence that pretreatment with TrkB-IgG before fixed-spaced shock impacted test performance (all $F$ values $<1.10, p>0.05$ ). It appears that the biological processes that underlie the abstraction of regularity, and the consequent dampening of any adverse effects due to shock treatment per se, do not depend on a ligand that acts at the TrkB receptor.

\section{Discussion}

Our results demonstrate that spinal systems are sensitive to whether a stimulus occurs in a fixed or variable manner and that these two forms of stimulation have divergent effects on function. Exposure to variable shock for 6-30 min undermined instrumental learning. Brief ( $6 \mathrm{~min}$ ) exposure to fixed-spaced shock also undermined learning, but extended exposure (30 min) did not. The learning deficit induced by variable stimulation was reversed by treatment with fixed-spaced shock, presented either immediately after or $24 \mathrm{~h}$ later. Conversely, fixed-spaced shock inhibited the induction of the learning deficit when administered before variable stimulation, and this protective effect lasted $48 \mathrm{~h}$. Administration of MK-801 before fixed-spaced shock, or cycloheximide immediately after shock delivery, eliminated the longterm protective effect. When variable stimulation was given in the presence of the BDNF scavenger TrkB-IgG, prior treatment with fixed-spaced shock had no effect. These results imply that spinal neurons can discriminate fixed and variable stimulation, that fixed-spaced stimulation engages a system that counters the consequences of variable stimulation, that the induction of this process requires extensive training, and that it has a lasting effect which depends on NMDAR function, protein synthesis, and BDNF.

\section{Evidence for temporal conditioning}

At a behavioral level, learning that an event occurs at regular intervals is sometimes characterized as a form of temporal conditioning. To claim that the consequences of fixed-spaced stimulation reflect a kind of conditioning requires evidence of learning: that the effect is not due to stimulus exposure per se, requires training (is acquired), and yields a lasting effect (memory). Further, because many examples of learning and memory depend on the NMDAR and protein synthesis (Morris et al., 1986; Schafe and LeDoux, 2000; Izquierdo et al., 2006), evidence that these processes are involved would provide converging support. We have shown that fixed-spaced stimulation has a lasting effect, that the encoding of temporal regularity requires extended training, and that presenting stimuli in a variable manner yields divergent results. Moreover, the long-term effect of fixed-spaced stimulation is blocked by drug manipulations that disrupt learning and memory. Together, our results suggest that the presentation of fixed-spaced stimulation evokes a form of learning.

What is less clear is whether the present results constitute a form of temporal conditioning. Applied to the present situation, we would have to assume that spinal neurons can encode the interval between each shock [the unconditioned stimulus (US)] and that this encoded interval functions a kind of Pavlovian conditioned stimulus (CS). At a minimum, this account anticipates that an external cue (a cutaneous CS) should have a protective effect similar to that observed with a fixed ISI. Supporting this, new data suggest that adding a Pavlovian signal (a $200 \mathrm{~ms}$ legshock) can block the induction of a learning deficit by variable tailshock. While intriguing, further work is needed to demonstrate that spinal neurons can encode a range of intervals. We have begun to address this issue, and have found that highfrequency $(5 \mathrm{~Hz})$ stimulation can also have a beneficial effect. This is important because it helps to discount an alternative interpretation of the present results - that variable stimulation has an adverse effect because it uniquely includes some closely spaced (0.2 ISI) shocks. Additional studies are examining whether spinal neurons can abstract regularity across distinct dermatomes and whether there is a form of savings across blocks of training.

We have previously shown that instrumental learning can both prevent and reverse the learning deficit induced by uncontrollable shock (Crown and Grau, 2001). This protective effect depends on BDNF (Huie et al., 2006) and instrumental learning is disrupted by pretreatment with an NMDAR antagonist (Joynes et al., 2004). The present results suggest that fixed-spaced shock has a similar effect and depends on some common neurochemical systems. The commonality may emerge, in part, because spinally mediated instrumental learning could reflect a type of Pavlovian conditioning, wherein proprioceptive cues that signal limb position serve as the CS and the onset of legshock functions as the US (Konorski and Miller, 1937; Grau and Joynes, 2005). From this perspective, pairing the proprioceptive cue (limb position) with shock onset endows the cue with the capacity to maintain an increased flexion response.

How do these two forms of learning compare? Instrumental learning is often observed after 180 shock exposures (Crown et al., 2002), far fewer than that needed to learn about temporal regularity. Yet, we typically assess the beneficial/protective effect of instrumental learning soon (10-120 min) after treatment because the consequences of response-outcome learning are not readily observed over longer retention periods (Baumbauer et al., 2006). In contrast, the protective effect of fixed-spaced shock was fully evident $48 \mathrm{~h}$ later. Also, subjects can learn about a fixed temporal relation after they have received variable stimulation, whereas instrumental learning is inhibited by prior exposure to variable stimulation and can only be reinstated if training is conducted in the presence of compounds that block the deficit (Crown and Grau, 2001). Because fixed-spaced stimulation can reverse the consequences of uncontrollable nociceptive input, and has a long-term effect, fixed-spaced stimulation may prove more useful in a clinical setting.

\section{Timing mechanisms}

Our results demonstrate that spinal neurons are sensitive to temporal relations, can discriminate fixed and variable stimulation, and that these two forms of stimulation have divergent effects on spinal cord function. It is not clear how the spinal cord encodes distinct temporal relations. One possibility is that fixed and variable stimuli engage distinct sets of sensory neurons, providing a type of filter that allows each to engage a distinct effect. However, from this perspective, it is not clear why a brief period of FT stimulation (180 shocks) engages a VT-like effect. Alternatively, the presentation of a shock may initiate a physiological process that has a distinct time course, providing a kind of hourglass that yields a time-dependent cue that could support conditioning (Boulos and Terman, 1980). The spinal cord could also gain a sense of time (a pacemaker) from the machinery that underlies the central pattern generators thought to mediate stepping (Kiehn, 2006; McCrea and Rybak, 2008). Some indirect support for the latter view comes from the observation that the time intervals at which the effects of fixed stimulation emerge lie within the frequency range of stepping (Roy et al., 1991; de Leon et al., 1994). Independent of how a temporal cue is generated, either of these accounts would need to posit that (in the absence of instru- 
mental control) shock engages a physiological process that inhibits learning, and only after extensive training is the opponent effect engaged.

Recent studies suggest that pattern detection can occur in other physiologically reduced preparations, including the isolated retina and visual cortex. For example, the isolated salamander and mouse retinas can detect alternating patterns of light/dark stimulation (Schwartz et al., 2007). After a pattern has been entrained, the ganglion cells exhibit increased spike bursting during stimulus omission that is precisely timed to when the missing stimulus should have occurred. Similarly, plasticity within the visual cortex is modulated by temporal regularity: fixed-spaced stimuli given at $1 \mathrm{~Hz}$ produces LTD, while stimuli given in a variable (Poisson) manner do not (Perrett et al., 2001). Like the isolated retina and visual cortex, the spinal cord is also sensitive to patterns of stimulation. In fact, the number of stimulus presentations (900) required to induce the divergent effects of variable and fixed stimulation are similar in the spinal cord and visual cortex. Further, each system requires NMDAR activation and BDNF release (Aicardi et al., 2004; Watt et al., 2004; Abidin et al., 2006; Yashiro and Philpot, 2008). What appears to set the spinal cord apart from systems like the retina is that extended training is required for the spinal cord to detect regularity within the stimulus train, whereas the retina is entrained to the pattern following a minimal amount of stimulation.

\section{Implications}

In intact subjects, exposure to an aversive stimulus can engage stress-related processes that undermine adaptive function (Overmier and Seligman, 1967; Seligman and Maier, 1967; Seligman, 1972; Shors, 2004). In many cases, the consequences of stimulation are reduced by instrumental control (Seligman et al., 1968, 1975) or introducing a Pavlovian cue (Seligman and Binik, 1977). Within the brain, the effects of instrumental control and Pavlovian cues appear to be mediated, in part, by distinct neural systems that can have divergent effects (Amat et al., 1998, 2008; Christianson et al., 2009). Surprisingly few studies have examined how introducing temporal regularity impacts the consequences of aversive stimulation. Instead, it appears that many implicitly assume that stress is enhanced by temporal uncertainty and design their experimental protocols using variable ISIs. If our work generalizes to other systems, it would suggest that introducing temporal regularity may do more than simply lessen the adverse effects of biological stressors. It may foster adaptive plasticity and active coping, perhaps through common neurochemical systems (e.g., enhanced BDNF release).

We have previously shown that uncontrollable nociceptive stimulation impairs recovery after a spinal cord injury (Grau et al., 2004). This is important because spinal injury is often accompanied by concurrent tissue damage that can provide a source of uncontrolled nociceptive input. Further, electrical stimulation is now used to engage motor behavior after spinal injury, both to engage motor systems to foster locomotion and to reduce muscle atrophy (Hook and Grau, 2007). Our prior work showed that introducing a level of instrumental control could reduce the adverse consequences of nociceptive stimulation. The present study demonstrates that simply presenting stimuli in a regular manner could lessen adverse side effects and foster adaptive plasticity that could promote recovery. Importantly, temporally regular stimulation can be applied even in cases where motor function is severely compromised, suggesting that this sort of stimulation may have considerable clinical value.

\section{References}

Abidin I, Köhler T, Weiler E, Zoidl G, Eysel UT, Lessmann V, Mittmann T (2006) Reduced presynaptic efficiency of excitatory synaptic transmission impairs LTP in the visual cortex of BDNF-heterozygous mice. Eur J Neurosci 24:3519-3531.

Aicardi G, Argilli E, Cappello S, Santi S, Riccio M, Thoenen H, Canossa M (2004) Induction of long-term potentiation and depression is reflected by corresponding changes in secretion of endogenous brain-derived neurotrophin factor. Proc Natl Acad Sci U S A 101:15788-15792.

Amat J, Matus-Amat P, Watkins LR, Maier SF (1998) Escapable and inescapable stress differentially alter extracellular levels of 5-HT in the basolateral amygdala of the rat. Brain Res 812:113-120.

Amat J, Paul E, Watkins LR, Maier SF (2008) Activation of the ventral medial prefrontal cortex during an uncontrollable stressor reproduces both the immediate and long-term protective effects of behavioral control. Neuroscience 154:1178-1186.

Baumbauer KM, Young EE, Hoy KC Jr, France JL, Joynes RL (2006) Intrathecal infusions of anisomycin impact the learning deficit but not the learning effect observed in spinal rats that have received instrumental training. Behav Brain Res 173:299-309.

Baumbauer KM, Young EE, Hoy KC Jr, Joynes RL (2007) Neurokinin receptors modulate the impact of uncontrollable stimulation on adaptive spinal plasticity. Behav Neurosci 121:1082-1094.

Baumbauer KM, Hoy KC Jr, Huie JR, Hughes AJ, Woller SA, Puga DA, Setlow B, Grau JW (2008) Timing in the absence of supraspinal input I: variable, but not fixed, spaced stimulation of the sciatic nerve undermines spinally-mediated instrumental learning. Neuroscience 155:1030-1047.

Boulos Z, Terman M (1980) Food availability and daily biological rhythms. Neurosci Biobehav Rev 4:119-131.

Christianson JP, Thompson BM, Watkins LR, Maier SF (2009) Medial prefrontal cortical activation modulates the impact of controllable and uncontrollable stressor exposure on a social exploration test of anxiety in the rat. Stress 12:445-450.

Crown ED, Grau JW (2001) Preserving and restoring behavioral potential within the spinal cord using an instrumental training paradigm. J Neurophysiol 86:845-855.

Crown ED, Ferguson AR, Joynes RL, Grau JW (2002) Instrumental learning within the spinal cord: IV. Induction and retention of the behavioral deficit observed after noncontingent shock. Behav Neurosci 116:1032-1051.

Davis HP, Squire LR (1984) Protein synthesis and memory: a review. Psychol Bull 96:518-559.

de Leon R, Hodgson JA, Roy RR, Edgerton VR (1994) Extensor- and flexorlike modulation within motor pools of the rat hindlimb during treadmill locomotion and swimming. Brain Res 654:241-250.

Dudek SM, Bear MF (1992) Homosynaptic long-term depression in area CA1 of hippocampus and the effects of NMDA receptor blockade. Proc Natl Acad Sci U S A 89:4363-4367.

Ferguson AR, Washburn SN, Crown ED, Grau JW (2003) GABA(A) receptor activation is involved in noncontingent shock inhibition of instrumental conditioning in spinal rats. Behav Neurosci 117:799-812.

Ferguson AR, Crown ED, Grau JW (2006) Nociceptive plasticity inhibits adaptive learning in the spinal cord. Neuroscience 141:421-431.

Ferguson AR, Bolding KA, Huie JR, Hook MA, Santillano DR, Miranda RC, Grau JW (2008) Group I metabotropic glutamate receptors control metaplasticity of spinal cord learning through a PKC-dependent mechanism. J Neurosci 28:11939-11949.

Flexner LB, Flexner JB, Stellar E (1965) Memory and cerebral protein synthesis in mice as affected by graded amounts of puromycin. Exp Neurol 13:264-272.

Gómez-Pinilla F, Huie JR, Ying Z, Ferguson AR, Crown ED, Baumbauer KM, Edgerton VR, Grau JW (2007) BDNF and learning: evidence that instrumental training promotes learning within the spinal cord by upregulating BDNF expression. Neuroscience 148:893-906.

Grau JW, Joynes RL (2005) A neural-functionalist approach to learning. Int J Comp Psychol 18:1-22.

Grau JW, Barstow DG, Joynes RL (1998) Instrumental learning within the spinal cord: I. Behavioral properties. Behav Neurosci 112:1366-1386.

Grau JW, Washburn SN, Hook MA, Ferguson AR, Crown ED, Garcia G, Bolding KA, Miranda RC (2004) Uncontrollable stimulation undermines recovery after spinal cord injury. J Neurotrauma 21:1795-1817.

Grau JW, Crown ED, Ferguson AR, Washburn SN, Hook MA, Miranda RC 
(2006) Instrumental learning within the spinal cord: underlying mechanisms and implications for recovery after injury. Behav Cogn Neurosci Rev 5:191-239.

Griffiths TD, Büchel C, Frackowiak RS, Patterson RD (1998) Analysis of temporal structure in sound by the human brain. Nat Neurosci $1: 422-427$.

Hall DA, Barrett DJ, Akeroyd MA, Summerfield AQ (2005) Cortical representations of temporal structure in sound. J Neurophysiol 94:3181-3191.

Hook MA, Grau JW (2007) An animal model of functional electrical stimulation: evidence that the central nervous system modulates the consequences of training. Spinal Cord 45:702-712.

Huie JR, Hoy KC, Miranda R, Grau JW (2006) BDNF facilitates learning in the rat spinal cord. Soc Neurosci Abstr 32:555.17.

Ivry RB, Spencer RM (2004) The neural representation of time. Curr Opin Neurobiol 14:225-232.

Izquierdo I, Bevilaqua LR, Rossato JI, Bonini JS, Medina JH, Cammarota M (2006) Different molecular cascades in different sites of the brain control memory consolidation. Trends Neurosci 29:496-505.

Joynes RL, Janjua K, Grau JW (2004) Instrumental learning within the spinal cord: VI. The NMDA receptor antagonist, AP5, disrupts acquisition and maintenance of an acquired flexion response. Behav Brain Res 154:431-438.

Karmarkar UR, Buonomano DV (2007) Timing in the absence of clocks: encoding time in neural network states. Neuron 53:427-438.

Kiehn O (2006) Locomotor circuits in the mammalian spinal cord. Annu Rev Neurosci 29:279-306.

Konorski JA, Miller SM (1937) On two types of conditioned reflex. J Gen Psychol 16:264-273.

Mauk MD, Buonomano DV (2004) The neural basis of temporal processing. Annu Rev Neurosci 27:307-340.

McCrea DA, Rybak IA (2008) Organization of mammalian locomotor rhythm and pattern generation. Brain Res Rev 57:134-146.

Morris RG, Anderson E, Lynch GS, Baudry M (1986) Selective impairment of learning and blockade of long-term potentiation by an $N$-methyl-Daspartate receptor antagonist, AP5. Nature 319:774-776.

Mulkey RM, Malenka RC (1992) Mechanisms underlying induction of homosynaptic long-term depression in area CA1 of the hippocampus. Neuron 9:967-975.

Nader K, Schafe GE, Le Doux JE (2000) Fear memories require protein synthesis in the amygdala for reconsolidation after retrieval. Nature 406:722-726.

Overmier JB, Seligman MEP (1967) Effects of inescapable shock upon subsequent escape and avoidance responding. J Comp Physiol Psychol 63:28-33.
Patton BC, Hook MA, Ferguson AR, Crown ED, Grau JW (2004) The behavioral deficit observed following noncontingent shock in spinalized rats is prevented by the protein synthesis inhibitor cycloheximide. Behav Neurosci 118:653-658.

Perrett SP, Dudek SM, Eagleman D, Montague PR, Friedlander MJ (2001) LTD induction in adult visual cortex: role of stimulus timing and inhibition. J Neurosci 21:2308-2319.

Rodrigues SM, Schafe GE, LeDoux JE (2004) Molecular mechanisms underlying emotional learning and memory in the lateral amygdala. Neuron 44:75-91.

Roy RR, Hutchison DL, Pierotti DJ, Hodgson JA, Edgerton VR (1991) EMG patterns of rat ankle extensors and flexors during treadmill locomotion and swimming. J Appl Physiol 70:2522-2529.

Schafe GE, LeDoux JE (2000) Memory consolidation of auditory Pavlovian fear conditioning requires protein synthesis and protein kinase $A$ in the amygdala. J Neurosci 20:RC96(1-5).

Schwartz G, Harris R, Shrom D, Berry MJ (2007) Detection and prediction of periodic patterns by the retina. Nat Neurosci 10:552-554.

Seligman M, Binik Y (1977) The safety signal hypothesis. In: Operant Pavlovian interactions (Davis H, Hurwitz H, eds) pp 165-188. Hillsdale, NJ: Erlbaum.

Seligman ME (1972) Learned helplessness. Annu Rev Med 23:407-412.

Seligman MEP, Maier SF (1967) Failure to escape traumatic shock. J Exp Psychol 74:1-9.

Seligman MEP, Maier SF, Geer JH (1968) Alleviation of learned helplessness in the dog. J Abnorm Psychol 73:256-262.

Seligman MEP, Rosellini RA, Kozak MJ (1975) Learned helplessness in the rat: reversibility, time course, and immunization. J Comp Physiol Psychol $88: 542-547$.

Shors TJ (2004) Learning during stressful times. Learn Mem 11:137-144.

Shors TJ, Foy MR, Levine S, Thompson RF (1990) Unpredictable and uncontrollable stress impairs neuronal plasticity in the rat hippocampus. Brain Res Bull 24:663-667.

Watt AJ, Sjöström PJ, Häusser M, Nelson SB, Turrigiano GG (2004) A proportional but slower NMDA potentiation follows AMPA potentiation in LTP. Nat Neurosci 7:518-524.

Yashiro K, Philpot BD (2008) Regulation of NMDA receptor subunit expression and its implications for LTD, LTP, and metaplasticity. Neuropharmacology 55:1081-1094.

Yau JM, Olenczak JB, Dammann JF, Bensmaia SJ (2009) Temporal frequency channels are linked across audition and touch. Curr Biol 19:561566. 